This item was submitted to Loughborough's Research Repository by the author.

Items in Figshare are protected by copyright, with all rights reserved, unless otherwise indicated.

\title{
Continuous membrane emulsification with pulsed (oscillatory) flow
}

PLEASE CITE THE PUBLISHED VERSION

http://dx.doi.org/10.1021/ie3020457

\section{PUBLISHER}

(c) American Chemical Society

\section{VERSION}

AM (Accepted Manuscript)

\section{LICENCE}

CC BY-NC-ND 4.0

\section{REPOSITORY RECORD}

Holdich, R.G., Marijana M. Dragosavac, Goran T. Vladisavljevic, and Emma Piacentini. 2014. "Continuous Membrane Emulsification with Pulsed (oscillatory) Flow”. figshare. https://hdl.handle.net/2134/14664. 
This item was submitted to Loughborough's Institutional Repository (https://dspace.lboro.ac.uk/) by the author and is made available under the following Creative Commons Licence conditions.

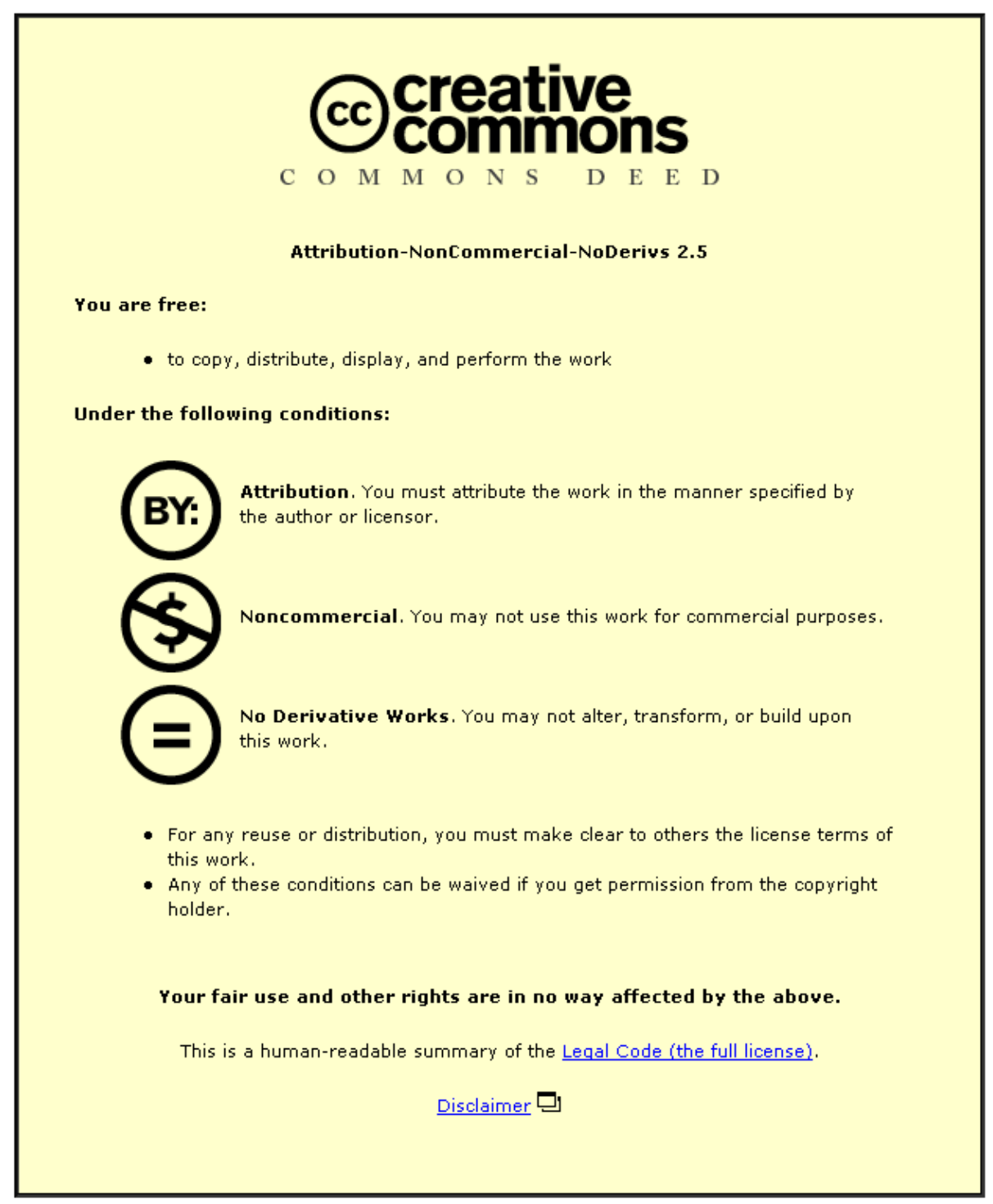

For the full text of this licence, please go to: http://creativecommons.org/licenses/by-nc-nd/2.5/ 


\title{
Continuous membrane emulsification with pulsed (oscillatory) flow
}

\author{
Richard G. Holdich ${ }^{1 *}$, Marijana Dragosavac ${ }^{1}$, Goran T. Vladisavljevic ${ }^{1}$, and \\ Emma Piacentini ${ }^{2}$ \\ ${ }^{1}$ Department of Chemical Engineering, Loughborough University, \\ Leicestershire, LE11 3TU, U.K. \\ ${ }^{2}$ Institute on Membrane Technology, Via P. Bucci 17/C, 87036 Rende (CS), Italy.
}

\begin{abstract}
Tubular micron pore sized sieve type membranes with internal diameter of $14 \mathrm{~mm}$ and length of $60 \mathrm{~mm}$ containing uniform pores of diameter 10 and $20 \mu \mathrm{m}$ were used to generate emulsions of sunflower oil dispersed in water and stabilised by Tween 20 using oscillatory flow of the continuous phase. Drop diameters between 30 and $300 \mu \mathrm{m}$ could be produced, in a controllable way and with span values of down to 0.4. By using pulsed flow it was possible to provide dispersed phase concentrations of up to $45 \% \mathrm{v} / \mathrm{v}$ in a single pass over the membrane, i.e. without the need to recirculate the continuous phase through the membrane tube. It was possible to correlate the drop size produced with the shear conditions at the membrane surface using the wave shear stress equation. The oscillatory Reynolds number indicated flow varying from laminar to substantially turbulent, but the change in flow conditions did not show a notable influence on the drop diameters produced, over what is predicted by the varying wall shear stress applied to the wave equation. However, the $20 \mu \mathrm{m}$ pore sized sieve type membrane appeared to allow the passage of the pressure pulse through the membrane pores, under certain operating conditions, which did lead to finer drop sizes produced than would be predicted. These through-membrane pulsations could be suppressed by changes in operating conditions: a higher dispersed phase injection rate or more viscous continuous phase, and they did not occur under similar operating conditions used with the 10
\end{abstract}


$\mu \mathrm{m}$ pore sized sieve type of membrane. Generating emulsions of this size using pulsed continuous phase flow provides opportunities for combining drop generation at high dispersed phase concentration, by membrane emulsification, with downstream processing such as reaction in plug flow reactors.

keywords

emulsification, sieve-membrane, force balance, oscillation, Reynolds number

*corresponding author's address:

Professor Richard Holdich, Department of Chemical Engineering, Loughborough University, Loughborough, Leicestershire, LE11 3TU, UK. Tel: +44 1509 222519, Fax: +44 1509 223923, e-mail: r.g.holdich@Lboro.ac.uk 


\section{Introduction}

Membrane emulsification (ME) is a process of forming an emulsion by injecting a liquid (dispersed phase), or preliminary emulsified mixture of two immiscible liquids, through a microporous membrane into the continuous phase ${ }^{1}$. In direct (“bottom-up”) ME processes, fine droplets of dispersed phase are produced by injecting a single phase through the membrane whereas in a pre-mix (“top-down”) ME process, fine droplets are produced by passing a pre-mix through the membrane. At low production rates, droplets can be formed in the absence of any shear force on the membrane surface, solely by the action of interfacial tension ${ }^{2}$. At small inter-pore distances, relative to the droplet diameter, the "push-off” force results from droplet deformation on the membrane surface, assisting in droplet detachment ${ }^{3}$. In order to obtain reasonably uniform droplets at commercially significant throughputs, shear stress is maintained at the membrane/continuous phase interface, usually by providing crossflow $^{4}$ or stirring 5 . To further increase droplet throughput in cross-flow ME, the continuous phase may be introduced into the membrane tube radially, thereby forming spiral streamlines in the axial direction ("swirl flow"), and these may exert a strong centrifugal force on the inner surface of the membrane ${ }^{6}$. Using swirl-flow ME with a Shirasu Porous Glass (SPG) membrane, it was possible to achieve a high transmembrane flux of $3 \mathrm{~m}^{3} \mathrm{~m}^{-2} \mathrm{~h}^{-1}$ resulting in a dispersed phase volume of $40 \%$ in a single pass, but at the expense of high shear stress at the membrane surface.

ME is often used for production of multiple emulsions ${ }^{7}$ and fragile particles, such as core/shell capsules ${ }^{\mathbf{8}, \mathbf{9}}$. In order to prevent breakage of shear sensitive materials, it is highly desirable to maintain low shear conditions in the bulk of the product stream, although shear 
stress at the membrane surface may be quite significant. Insertion of static turbulence promoters is one method of increasing shear stress at the membrane surface, while maintaining a low shear in the recirculation loop ${ }^{\mathbf{1 0}}$. An alternative method of keeping low shear away from the membrane surface is to replace the commonly used stationary membrane by a moving membrane, in which case droplet detachment from the membrane surface is facilitated by rotating ${ }^{11-13}$ or vibrating ${ }^{14,15}$ the membrane within an otherwise static continuous phase. In moving membrane systems, shear stress on the membrane surface is decoupled from cross-flow velocity, because surface shear is controlled by the speed of membrane rotation, or the frequency and amplitude of membrane oscillation. In these systems, crossflow is normally applied only to recover the droplets produced in the module and not to assist in droplet generation process. Sufficient shear on the membrane surface can be achieved no matter how small the flow rate of the continuous phase may be, and thus, emulsions with a high dispersed to continuous phase ratio can be produced in a single pass of the continuous phase, without the necessity of high shear within the fluid which may damage shear sensitive components or the larger drops formed.

Micron pore sized sieve type membranes are increasingly being used in ME, because they can afford much higher transmembrane fluxes than Shirasu Porous Glass membrane, or sintered alumina membranes ${ }^{\mathbf{9 , 1 2 , 1 6}}$. They are ultra-thin foils with rectilinear pores and low internal pore area, and are less prone to fouling by emulsion ingredients than the highly tortuous SPG membranes, as the sieve type of membrane does not have any internal surface, or structure, on which that fouling can occur.

Pulsed flow has been widely used to enhance mixing and heat and mass $\operatorname{transfer}^{17}$ in fluidized bed columns ${ }^{18}$, ultrafiltration and microfiltration modules ${ }^{19}$, continuous flow tubular 
reactors $^{20}$, solvent extraction columns ${ }^{21}$, adsorption columns ${ }^{22}$, etc. However, there has been no work published on using pulsed (oscillatory) flow in membrane emulsification. Pulsed flow ME is an alternative method of producing emulsions with a high dispersed to continuous phase ratio continuously in a single-pass operation of the continuous phase. The potential benefits of pulsed flow over vibrating ME are: (i) pulsed flow ME requires less energy than vibrating ME; (ii) pulsed flow ME does not require a special module design, i.e. conventional tubular cross flow membranes can be used in pulsed flow mode; (iii) the consumption of energy to maintain pulsed flow is virtually independent of the membrane area, whereas in a vibrating ME system the energy consumption is higher for larger membrane surface area, and (iv) pulsed flow in the continuous phase can be extended to a baffled reactor, connected in series to the membrane module, to achieve simultaneous drop generation and chemical/physicochemical reaction in the produced emulsion. Pulsed flow is being used to convert batch processes, e.g. reactions, to continuous ones and there has been work published previously on the desire to produce polymer particles continuously based on membrane emulsification $^{23}$, but based on cross-flow emulsification rather than generation using oscillation of the liquid flow field.

However, obtaining an accurate description of the fluid mechanics of the oscillatory flow next to the surface of the membrane is not as simple as in the shear flow that results from cross-flow operation. Such a description is warranted for the purposes of modelling and understanding the droplet generation process, and previous work ${ }^{15,16,24}$ successfully modelled the drop generation process when the flow field next to the membrane surface could be defined. Under such circumstances a simple shear - capillary force balance model can be deduced, relating the drop diameter $(x)$ to the prevailing shear stress $(\tau)$ : 


$$
x=\frac{\sqrt{18 \tau^{2} r_{p}^{2}+2 \sqrt{81 \tau^{4} r_{p}^{4}+4 r_{p}^{2} \tau^{2} \gamma^{2}}}}{3 \tau}
$$

where $r_{p}$ is the pore radius and $\gamma$ is the interfacial tension. Under conditions when the shear is consistent the shear to use in equation (1) is that value of consistent shear stress. However under conditions of variable shear, such as during oscillation of the membrane, it has been found that the most appropriate shear to use is the maximum value; provided that there is at least one maximum peak shear "event” per drop that is generated ${ }^{\mathbf{1 5}}$. A peak shear event occurs twice per oscillation: once in each direction that the wave is moving, for a regular wave form such as a sine wave. Equation (1) suggests that the drop size is independent of the dispersed phase injection rate, which is true only for a limited range of what is called the “dripping” regime: this exists where the drops are sheared off the membrane surface rapidly and there is negligible inertial contribution from the dispersed phase to the drop size, only viscous drag and capillary forces are relevant. On increasing the dispersed phase injection rate single drops may still be detached from the membrane surface; i.e. the dripping regime, but the drop size may increase slightly. On increasing the dispersed phase flow rate further it is possible to change from the dripping regime into the jetting regime: when a jet of liquid discharges from a pore and the droplets are formed by jet breakup in the prevailing conditions of the continuous phase as well as the dispersed phase.

Another factor that may increase the drop size with increasing dispersed phase injection rate is the 'dynamic' interfacial tension effect. Techniques to measure interfacial tension provide the equilibrium value, but a newly formed drop emerging from a membrane pore has a growing surface and finite time is required for the stabilising surfactant to transfer and attach to the newly formed surface. Hence, this dynamic interfacial tension will be greater than the measured equilibrium value as the surfactant concentration at the two liquid phase boundary 
will be less than that found when measuring under equilibrium conditions. A greater interfacial tension will provide larger drops, as indicated by equation (1). When using small molecular surfactants to stabilise larger drops, in the order of over 20 microns, the influence of dynamic interfacial tension is not normally considered significant ${ }^{25}$.

In pulsed, or oscillatory, flow the continuous phase velocity will vary up to a maximum, slow and then reverse in direction. This will give rise to varying shear and varying ratio of inertial to viscous forces within the fluid. The oscillatory Reynolds number based on the peak velocity is given by:

$$
\operatorname{Re}_{0}=\frac{2 \pi f a \rho d}{\mu}
$$

where $f$ is the frequency of oscillation, $a$ is the amplitude, $\rho$ is the liquid density, $d$ is the internal tube diameter and $\mu$ is the liquid viscosity. Hence as the velocity is varying, during oscillatory flow it is possible for the flow to vary from turbulent to laminar, and back again, within one cycle of the pulsation. The commonly used boundaries to distinguish the different flows are provided in Table $1^{\mathbf{2 6}}$. In the case of oscillatory baffled systems, it is generally desirable to operate in a region of oscillatory Reynolds number up to $300^{\mathbf{1 7}}$, in the laminar and disturbed laminar regime, to ensure consistency of operation. However, operating conditions in the more turbulent regions are readily obtained in aqueous systems when aiming to produce smaller drops, significantly less than $100 \mu \mathrm{m}$. Hence, this study investigated the ability to control the drop size being produced under varying flow conditions from laminar to significantly turbulent oscillatory Reynolds numbers.

There have been numerous investigations of the Stokes boundary layer in oscillatory flow ${ }^{\mathbf{2 6}}$, applicable when in the turbulent regime. It is within this boundary layer that the drops will be 
generated during membrane emulsification, when operating at relatively high oscillatory Reynolds number. The Stokes boundary layer thickness $(\delta)$ is given by:

$$
\delta=2 \pi \sqrt{\frac{\mu}{\pi f \rho}}
$$

So, in water systems using a frequency of 10 and $50 \mathrm{~Hz}$ the Stokes boundary layer thicknesses would be expected to be 1100 to 500 microns. Superficially, if generating drops significantly with diameters below these values may lead to the conclusion that the drops will be produced in a quiescent boundary layer and the bulk turbulence is not important, provided it is not sufficient to damage the drops after they have been formed. However, the occurrence of increasing amounts of "turbulent bursts" with increasing Reynolds number is also recorded $^{\mathbf{2 6}}$; these are turbulent eddies that originate at the wall of the pipe, i.e. the membrane surface, that are then ejected into the bulk flow of the continuous phase. Clearly, these turbulent eddies are likely to have an influence on the drop size of the emerging dispersed phase from the membrane pore and the presence of a growing surface at the tube wall would be expected to encourage this type of eddy formation in the continuous phase.

If the occurrence of turbulence and bursts near the membrane surface can be neglected, then it may be possible to correlate drop size with the shear stress at the membrane surface based on the wave equation for shear stress:

$$
\tau=v_{o}\left(\frac{\omega_{f} \mu \rho}{2}\right)^{1 / 2}\left[\sin \left(\omega_{f} t\right)-\cos \left(\omega_{f} t\right)\right]
$$

where $\omega_{f}$ is the angular frequency, determined by:

$$
\omega_{f}=2 \pi f
$$

where $f$ is the frequency of the oscillation and $v_{0}$, is the peak velocity related to both the angular frequency and the amplitude (a) of oscillation by the equation: 


$$
v_{o}=\omega_{f} a
$$

A peak shear event occurs when the value of wall shear provided by equation (4) is at a maximum:

$$
\tau_{\max }=\omega_{f}^{3 / 2} a(\mu \rho / 2)^{1 / 2}=2 a(\pi f)^{3 / 2}(\mu \rho)^{1 / 2}
$$

The maximum shear occurs twice per cycle, and it is the maximum shear that is used in equation (1) for drop size.

The aim of the work reported here was to investigate drop generation in a novel ME system with pulsed (oscillatory) flow of the continuous phase in a tubular micron pore sized sieve type of membrane. The main emphasis was to investigate the effect of amplitude and frequency of flow oscillation (or pulsation), superimposed on a low mean cross-flow velocity, on the size and uniformity of generated droplets with some consideration of the prevailing fluid condition as determined by the oscillatory Reynolds number. The effects of pore size, continuous phase viscosity and dispersed and continuous phase flow rates were investigated.

\section{Materials}

The oil in water emulsions (O/W) were prepared using commercially available food grade sunflower oil as the dispersed phase and 2\% w/w Tween 20 (polysorbate 20 or polyoxyethylene sorbitan monolaurate, Sigma Aldrich, UK) as the continuous phase. In a series of experiments in which the influence of the dispersed phase viscosity on the droplet size was investigated, 0.4\% w/w methyl hydroxypropyl cellulose (MHC) (Methofas, PL, Imperial Chemical Industries, UK) was used in combination with 2\% w/w Tween 20 as the continuous phase.

The interfacial tension at the sunflower and surfactant solution interface was measured by processing the images of pendant drops acquired by a video camera using a drop shape 
analysis system (DSA 10, Krüss, Hamburg, Germany). The viscosity of the continuous phase using 2\% w/w Tween 20 and $0.4 \%$ w/w methyl hydroxypropyl cellulose was measured using a rotational viscometer with a temperature-controlled concentric cylinder measurement cell (ViscoTester 550, Thermo Haake, Germany). The values of the interfacial tension and viscosity are listed in Table 2.

\section{Membranes and Membrane Module}

The oil-in-water emulsions were produced using a pulsed flow system with tubular hydrophilic micron pore sized sieve type nickel membranes. Both the membrane and the pulsed flow system were supplied by Micropore Technologies Ltd. (Hatton, Derbyshire, UK).

The pulsed system is illustrated in Figure 1. The dispersed and continuous phases were injected using peristaltic pumps (Watson-Marlow Sci-Q 400 Pump, Cornwall, UK). An accelerometer (PCB Piezotronics model M352C65) was connected to a National Instruments Analogue to Digital converter (NI eDAQ-9172) which was interfaced to a LabView executable program running on a PC. The information provided by the program from the accelerometer was the frequency and amplitude of the oscillation: the frequency being determined by the direction of travel, and the amplitude was deduced from the acceleration measurement. The oscillation signal was provided by a National Instrument frequency generator, which fed a power amplifier driving the electro-mechanical oscillator which was connected to a bellows designed for use in a diaphragm pump, which was submerged in the continuous phase and its oscillation provided pulsation of the liquid. This electro-mechanic means to generate pulsed flow provided separate control of frequency and amplitude to enable a systematic investigation of the influence of these parameters, within a range of 0 to $50 \mathrm{~Hz}$ and 0 to $1.6 \mathrm{~mm}$ amplitude within the membrane tube. A single membrane tube was 
used with an internal diameter of $14 \mathrm{~mm}$ and working length of $60 \mathrm{~mm}$; the effective membrane area was $26 \mathrm{~cm}^{2}$. Two pore diameter membranes were investigated: 10 and $20 \mu \mathrm{m}$ and the spacing between the pores was $200 \mu \mathrm{m}$ in both systems; the surface porosity was, therefore, 0.2 and $0.9 \%$, respectively.

\section{Experimental set-up and procedure}

Before each experiment, the membrane was cleaned with commercially available soap in an ultrasonic bath for 5 min followed by treatment in $4 \mathrm{M} \mathrm{NaOH}$ solution for 5 min and finally pre-soaked in a wetting agent (Micropore Technologies Ltd) for at least 30 minutes to increase the hydrophilicity of the surface. To prevent pulse-damping, due to the presence of air within the system, both the outer and inner sides of the membrane were filled with continuous phase prior to the experiment and all the air was purged through the purge valves. The sunflower oil was injected through the membrane at a constant flow rate of between 0.5-

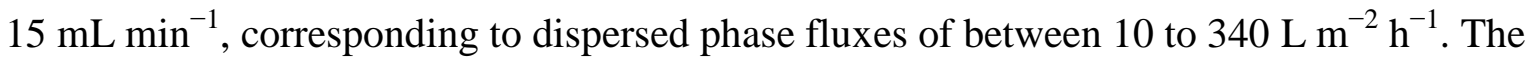
continuous phase was pulsed along the membrane module at various frequencies and the flow rate of the continuous phase was in the range between $0-72 \mathrm{~mL} \mathrm{~min}^{-1}$, without any recirculation of the continuous phase. The emulsion droplets were collected in a stirred tank that was agitated slowly and were analyzed as specified below.

\section{Determination of mean droplet size and droplet size distribution}

Droplet size distribution for all samples was measured by laser light diffraction using a Malvern Mastersizer (model S). For each emulsion, three separate samples and measurements were performed and the mean average of these is reported. The average droplet diameter is expressed as the volume median diameter $\mathrm{D}(V, 0.5)$, which is the diameter corresponding to 
$50 \%$ on the cumulative volume distribution curve. Droplet size uniformity is expressed as the span of a distribution:

$\operatorname{span}=\frac{D(V, 0.9)-D(V, 0.1)}{D(V, 0.5)}$

where $\mathrm{D}(\mathrm{V}, 0 . x)$ is the diameter corresponding to $x 0 \%$ on a cumulative volume droplet size curve. A Leitz Ergolux optical microscope was used to confirm the droplet size reported by the Malvern Mastersizer S and to take photomicrographs of the prepared emulsions.

\section{Results \& Discussion}

Figure 2 illustrates duplicate and triplicate tests for the emulsion droplet diameter as a function of frequency of pulse oscillation when using the 20 micron membrane with an amplitude of $1.6 \mathrm{~mm}$ (i.e. peak to peak displacement value of $3.2 \mathrm{~mm}$ ) and $5 \mathrm{~mL} \mathrm{~min}{ }^{-1}$ injected with a crossflow rate of $72 \mathrm{~mL} \mathrm{~min}^{-1}$. Hence, this provided an emulsion with a volume concentration of oil in water of $7 \% \mathrm{v} / \mathrm{v}$ in a single pass of the continuous phase; i.e. there was no recirculation of the continuous phase other than that provided by the oscillation. At the lowest frequency, $10 \mathrm{~Hz}$, the mean droplet diameter was $87 \mu \mathrm{m}$, with spans ranging from 0.7 to 0.8 . As expected from Eq. (1), the largest droplets were produced at the lowest frequency due to the lowest shear force acting on the droplets. In general, the reproducibility of the data is reasonable, but it is also noticeable that there is limited control over the drop size by changing the frequency of the liquid oscillation: from $20 \mathrm{~Hz}$ upwards the drop size remains in the range between 50 and $60 \mu \mathrm{m}$. It is notable that this is approximately three times the membrane pore diameter, which is often deemed to be the relation between the drop and pore size during crossflow membrane emulsification ${ }^{27}$. 
Better control of drop size under various operating conditions was obtained when using a 10 $\mu \mathrm{m}$ pore size membrane. Figure 3 illustrates the performance of this membrane at various dispersed phase injection rates between 0.5 and $13.4 \mathrm{~mL} \mathrm{~min}^{-1}$. This generated emulsions with a dispersed phase volume concentration of between 1.7 and $45 \% \mathrm{v} / \mathrm{v}$, in a single pass in terms of continuous phase cross-flow over the membrane surface. The injection rate vs. drop diameter plot also provides information on the performance of the membrane in the context of dripping and possible jetting of the dispersed phase into the continuous phase. In Figure 3(a) it is notable that the drop size remains just below $50 \mu \mathrm{m}$ for injection rates up to $4 \mathrm{~mL}$ $\min ^{-1}$, but increases between 4 and $10 \mathrm{~mL} \mathrm{~min}^{-1}$. Hence, it is likely that the $10 \mu \mathrm{m}$ membrane was operating within the dripping regime at an injection rate of $4 \mathrm{~mL} \mathrm{~min}^{-1}$ or below. When operating within the jetting regime it is normal to expect the uniformity of the drops to suffer, however the span when using $9.7 \mathrm{~mL} \mathrm{~min}^{-1}$ is very similar to the span when operating at the

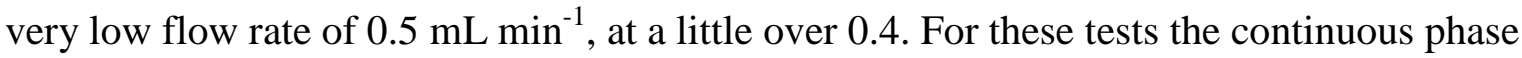
crossflow rate was only $30 \mathrm{~mL} \mathrm{~min}^{-1}$, hence an injection rate of $9.7 \mathrm{~mL} \mathrm{~min}^{-1}$ results in a dispersed phase concentration of over $32 \% \mathrm{v} / \mathrm{v}$, in a single pass in terms of continuous phase cross-flow.

Figure 4 provides two images, at the same magnification (see the $100 \mu \mathrm{m}$ scale bar), to illustrate the emulsions formed at 0.5 and $9.7 \mathrm{~mL} \mathrm{~min}^{-1}$ injection rates. They both have a span value of just over 0.4 , but the visual appearance of the two emulsions is noticeably different due to significantly different median droplet sizes of 46 and $88 \mu \mathrm{m}$. All emulsification conditions were kept constant, except the injection rate. It is notable that in Figure 4(b) the drop size is much larger than in Figure 4(a) and that it appears to be bimodal: with uniform drops of a larger and smaller size, rather than a range of sizes around a single modal value. The uniformity of these drops is good, as reported by the instrumental technique based on laser light diffraction because the volume distribution is biased towards the larger sizes, see 
Figure 5. It is noticeable that there is a complete lack of fine particles smaller than $20 \mu \mathrm{m}$, or excessively large drops, above $140 \mu \mathrm{m}$ in diameter. From the evidence illustrated in Figures 3 to 5 it appears that the system is operating in the jetting mode at an injection rate of $9.7 \mathrm{~mL}$ $\min ^{-1}$, but despite this the span value of the emulsion produced is reasonable at 0.4 and a concentrated emulsion (32\% v/v) can be produced.

In previous studies using an oscillating membrane within an otherwise stationary liquid ${ }^{15}$ it was possible to correlate the drop size formed with the shear stress at the membrane surface, using equation (1). A similar correlation was performed for the drops arising from the $10 \mu \mathrm{m}$ pore size membrane, as illustrated in Figure 6. The figure also contains data illustrating the lack of any influence of the cross-flow rate on the drop size obtained: cross-flow rates of 30 and $72 \mathrm{~mL} \mathrm{~min}^{-1}$ provide very similar data for drop size as a function of frequency which means that under these operating conditions the drop detachment was controlled by the flow pulsations rather than steady flow of the continuous phase. The data illustrates that the drop size is controllable in the size range between 270 and $30 \mu \mathrm{m}$, depending on the frequency used for the oscillation. Again the lower limit, $30 \mu \mathrm{m}$, is close to the expected 3 times the pore diameter $^{27}$. For the purpose of modelling using Eqs. (1) and (7), two different interfacial tensions have been used; the values reported in Table 2 which are $2.5 \mathrm{mN} \mathrm{m}^{-1}$ and $4 \mathrm{mN} \mathrm{m}^{-1}$. The latter is the value found for the previously reported work on oscillating membranes. The sunflower oil was obtained from the same source, hence the newly measured value was unexpectedly low, but it may be due to between-batch variation of the components within the sunflower oil. The two curves, resulting from the two different interfacial tensions, are presented for comparison purposes. In either case, the measured drop size is slightly larger than the predicted ones, at the intermediate frequencies. This is usual as the drop size prediction model, equation (1), is only valid at a very low injection rates. At higher injection 
rates the drop has time to grow in size before it experiences a peak shear event ${ }^{\mathbf{1 6}}$; which is the cause of the drop to be sheared off the membrane surface. The drop size found at zero frequency, i.e. just a very low shear due to cross-flow, is about $270 \mu \mathrm{m}$. This is lower than the predicted drop size at low shear, but the inter-pore spacing is only $200 \mu \mathrm{m}$ and when the drops are larger than this they interfere with each other and an additional force has been reported previously to cause them to detach ${ }^{3}$. Hence, the data illustrated in Figure 6 suggests that the pulsed flow membrane emulsification when using the $10 \mu \mathrm{m}$ pore size membrane is fairly predictable and logical, with good control over the drop size obtained by varying the frequency of oscillation. There is no influence of bulk (continuous) phase cross-flow velocity, within the range tested, which is due to the very limited contribution of the bulk velocity when compared to the velocity due to oscillation. The peak wall shear rate obtained from oscillation is $797 \mathrm{~s}^{-1}$, when oscillating at just $10 \mathrm{~Hz}$ and $1.6 \mathrm{~mm}$ amplitude, whereas the wall shear rate from the cross-flow is $4.5 \mathrm{~s}^{-1}$ when pumping the continuous phase at the maximum flow rate used: $72 \mathrm{~mL} \min ^{-1}$. Hence, the contribution towards wall shear due to the cross-flow pumping is negligible, and the drop size is only dependent on oscillation conditions and not cross-flow rate. Another aspect to the consistency found in Figure 6 is the apparent lack of any influence due to the variable nature of the flow regimes found at oscillatory Reynolds number varying from 1400 to 7300 corresponding to the 10 to $50 \mathrm{~Hz}$ tests.

Predictable and consistent behaviour was not observed when using a $20 \mu \mathrm{m}$ pore size membrane. Figure 7 illustrates the variation of drop diameter with oscillatory Reynolds number. Similar inconsistent trends are observed when plotting drop size against either frequency, or wall shear stress. A general trend of reducing drop size with Reynolds number is shown, but with notable outliers: drop sizes of 66 and $90 \mu \mathrm{m}$ at Reynolds numbers less than 2000. These are values that provide significant turbulence, see Table 1 , so it is possible 
that detachment could be due to this, but it is notable that such behaviour did not exist when using the $10 \mu \mathrm{m}$ pore size membrane. Hence, it has to be concluded that the inconsistent behaviour is due to the nature of the $20 \mu \mathrm{m}$ membrane in the system, rather than an explanation due to transitions in the flow field from laminar to turbulent. At oscillatory Reynolds numbers greater than 5000 the drop size remained constant at a value of close to 50 $\mu \mathrm{m}$, with a generally decreasing trend in span value with increasing Reynolds number. This implies that it is unlikely that the drops are breaking up in the shear field due to turbulence: this increases as drop uniformity increases, whereas turbulence would be expected to give rise to decreasing uniformity. Furthermore, the reproducibility of the tests at oscillatory Reynolds numbers close to 6000, 2200 and 1500 were checked by replicate experiments and found to be good: the error bars on Figure 7 represent the range of the results provided from the different tests.

On further investigation of the experimental apparatus when using the $20 \mu \mathrm{m}$ pore size membrane, it was notable that pulsing could be observed within the oil reservoir side of the membrane system. The pulsation was, therefore, capable of passing through the membrane pores due to the very low resistance offered by the micron pore sized sieve type of membrane structure, see Figure 1. This pulsation was absent from tests performed using the $10 \mu \mathrm{m}$ pore size membrane. It was also less noticeable with the $20 \mu \mathrm{m}$ pore size membrane at higher frequencies. Both erroneous data points in Figure 7 were obtained at a frequency of $10 \mathrm{~Hz}$. Further information illustrating this aspect is shown in Table 3, where experiments were conducted to specifically test the ability of the pulse to pass through the membrane pore structure. 
In Table 3 two data points are shown with zero oscillation, just a crossflow of $72 \mathrm{~mL} \mathrm{~min}{ }^{-1}$. The shear stress at the membrane surface is negligible and drop sizes of 270 and $340 \mu \mathrm{m}$ result (depending on the injection rate used). The inter-pore spacing is again $200 \mu \mathrm{m}$, so drops of this size are consistent with drop detachment from the membrane being influenced by this spacing. When pulsing and using a relatively high injection rate, $15 \mathrm{~mL} \mathrm{~min}^{-1}$, the drop size is larger than the lower injection rate, $5 \mathrm{~mL} \mathrm{~min}^{-1}$. For frequencies 15 and $20 \mathrm{~Hz}$ this is 85 and $65 \mu \mathrm{m}$; and 74 and $57 \mu \mathrm{m}$, respectively. This is consistent with drop size increasing with injection rate, as observed previously ${ }^{\mathbf{1 6}}$. However, when oscillating at $10 \mathrm{~Hz}$ this difference is very much more prevalent: 217,87 and $47 \mu \mathrm{m}$ as the dispersed phase injection rate is reduced from 15 , to 5 to $0.5 \mathrm{~mL} \mathrm{~min}^{-1}$, respectively. It is postulated that the pulsing through the membrane is dampened when operating at the higher injection rate, 15 $\mathrm{mL} \mathrm{min}^{-1}$, hence the drop size produced, $217 \mu \mathrm{m}$, is closer to what would be expected given the prevailing conditions of shear at the membrane surface. This was investigated further by thickening the continuous phase using the thickening agent. The continuous phase viscosity was 30 times that used previously and operating under these conditions it was possible to produce a drop diameter of $140 \mu \mathrm{m}$ at a dispersed phase concentration of $15 \% \mathrm{v} / \mathrm{v}$ in a single pass of the continuous phase, without noticeable pulse action passing through the membrane pores of the micron sized sieve type membrane. Again the resulting larger drop size is deemed to be provided by successful suppression of the pulse from passing through the 20 $\mu \mathrm{m}$ membrane pores, due this time to the higher viscosity of the continuous phase.

\section{Conclusions}

There are many different methods for generating shear at the surface of a membrane for the purpose of membrane emulsification; e.g. by pumping (cross-flow), stirring, rotating a membrane (or a surface close-by), oscillating the membrane and in the case discussed here: by pulsing the flow over the membrane surface formed from a tube. This method has a 
particular advantage of being capable of being interfaced with a reactor downstream of the droplet generation stage, e.g. in the case of the formation of polymer particles, coacervates, etc. where the oscillatory nature of the flow can be used to provide good mixing and conditions approaching plug flow within the reactor. This provides attractive possibilities for integrated Chemical Engineering systems where dispersed phases are used, and would be ideal for many potentially continuous processes; where drop formation, reaction and even functionalization could be achieved continuously. Another extremely attractive aspect is the ability to produce very high disperse phase concentrations, approaching $50 \% \mathrm{v} / \mathrm{v}$, in a single pass of the continuous phase over the membrane surface: i.e. without the need for recirculation of the continuous phase. This is particularly advantageous when producing dispersions of larger drop size, where the otherwise required circulation would lead to drop damage within the pump and other fittings present. However, in order to realise these substantial potential advantages it is important to understand the factors and conditions that influence the process of droplet generation in pulsed flow.

Oscillatory flow has complex fluid mechanics, and there are a number of papers published on the Stokes boundary layer, which is the region in which the droplet generation will take place for oscillatory Reynolds numbers higher than 550. The very process of oscillation leads to a flow field that cannot be described as 'developed', as may be assumed to be the case during cross-flow emulsification. In fact, the velocity will vary during the pulse; in many cases it will change from conditions that may be described as laminar through to turbulent and back to laminar again. This occurs in flows with oscillatory Reynolds numbers between 100 and 3600. Above this value the flow is turbulent for all of the cycle. The occurrence of turbulence promotes turbulent bursts at the wall, and it would be logical to expect the presence of a growing obstruction, i.e. a droplet, encouraging such a burst. However, at the sizes of drops investigated in this paper the existence of this complex set of fluid conditions appeared to 
have no influence on the process: it was possible to correlate the drop size formed during membrane emulsification with a simple shear based model, for the $10 \mu \mathrm{m}$ pore sized membrane. However, this simple situation is unlikely to be the case with smaller drop sizes, produced using oscillating flow at much higher oscillating Reynolds numbers, where turbulence is more likely to influence the results.

The micron pore sized sieve type membrane has many advantages for the process of membrane emulsification, primarily the very low pressure drop needed to inject the dispersed phase into the continuous phase, due to the lack of an internal tortuous pore channel; unlike the glass, ceramic and sintered metal membranes. The sieve type is also much less prone to fouling for the same reasons, but the lack of tortuous pore channel means that it is easier for a pressure pulse to pass through the membrane from the receiving side where the continuous phase is present and into the side of the membrane where the dispersed phase is present. This may cause mixing around the pore on the dispersed phase side of the membrane leading to drop sizes that are much smaller than would be expected from the prevailing conditions of wall shear, a situation similar to what occurs during pre-mix emulsification. This was apparent when using a $20 \mu \mathrm{m}$ membrane pore sized sieve type membrane. However, this effect was not evident when using a $10 \mu \mathrm{m}$ pore sized membrane. It was possible to suppress the mixing described by increasing the flow rate of the injected phase and by increasing the viscosity of the continuous phase. It is unlikely that the other types of membranes mentioned: glass, ceramic and sintered would be as influenced by pulsation passing through the membrane, due to their greater hydraulic resistance caused by their tortuous pore channel structure.

Using a $10 \mu \mathrm{m}$ pore sized sieve type membrane it was possible to generate drops with a controllable median drop size of between 30 and $270 \mu \mathrm{m}$, with span values of significantly less than unity, and a value of $\sim 0.4$ at best. The wall shear model used to correlate the 
experimental drop size with shear stress appeared to provide a reasonable fit for the data, with the usual deviation from the model: increasing drop size with increasing disperse phase injection rate. The maximum dispersed phase concentration achieved was $45 \% \mathrm{v} / \mathrm{v}$ without any recycling of the continuous phase; i.e. in a single pass of the pumped continuous phase. It is likely that pulsed generation of emulsions, followed where appropriate by reaction and other unit operations, will become a significant technology in the conversion of existing batch process to continuous ones.

\section{Acknowledgements}

This work was partially supported by “POR Calabria FSE 2007/2013- Asse IV - Obiettivo operativo M2” (postdoctoral fellowship). 


\section{References}

(1) Vladisavljević, G.T.; Williams, R.A. Recent developments in manufacturing emulsions and particulate products using membranes. Adv. Colloid Interface Sci. 2005, 113, 1.

(2) Kukizaki, M. Shirasu porous glass (SPG) membrane emulsification in the absence of shear flow at the membrane surface: Influence of surfactant type and concentration, viscosities of dispersed and continuous phases, and transmembrane pressure. J. Membr. Sci. 2009, 327, 234.

(3) Kosvintsev, S.R.; Gasparini, G.; Holdich, R.G. Membrane emulsification: Droplet size and uniformity in the absence of surface shear. J. Membr. Sci. 2008, 313, 182.

(4) Vladisavljević, G.T.; Lambrich, U.; Nakajima M.; Schubert H. Production of O/W emulsions using SPG membranes, ceramic $\alpha-\mathrm{Al}_{2} \mathrm{O}_{3}$ membranes, microfluidizer and a microchannel plate: a comparative study. Colloid. Surf. A. 2004, 232, 199.

(5) Dragosavac, M.M.; Sovilj, M.N.; Kosvintsev, S.R.; Holdich, R.G.; Vladisavljević, G.T. Controlled production of oil-in-water emulsions containing unrefined pumpkin seed oil using stirred cell membrane emulsification. J. Membr. Sci. 2008, 322, 178.

(6) Shimoda, M.; Miyamae, H.; Nishiyama, K.; Yuasa, T.; Noma, S.; Igura, N. Swirl-Flow Membrane Emulsification for High Throughput of Dispersed Phase Flux through Shirasu Porous Glass (SPG) Membrane. Journal of Chemical Engineering of Japan 2011, 44, 1.

(7) Dragosavac, M.M.; Holdich, R.G.; Vladisavljević, G.T.; Sovilj, M. Stirred cell membrane emulsification for multiple emulsions containing unrefined pumpkin seed oil with uniform droplet size. J. Membr. Sci. 2012, 392, 122. 
(8) Pan, X.; York, D.; Preece, J.A.; Zhang, Z. Size and strength distributions of melamineformaldehyde microcapsules prepared by membrane emulsification. Powder Technol. 2012, 227, 43.

(9) Wagdare, N.A.; Marcelis, A.T.M.; Boom, R.M.; van Rijn, C.J.M. Porous microcapsule formation with micron pore sized sieve emulsification. J. Colloid Interface Sci. 2012, 355, 453.

(10) Koris, A.; Piacentini, E.; Vatai, G.; Bekassy-Molnar, E.; Drioli, E.; Giorno, L. Investigation on the effects of a mechanical shear-stress modification method during crossflow membrane emulsification. J. Membr. Sci. 2011, 371, 28.

(11) Vladisavljević, G.T.; Williams, R.A. Manufacture of large uniform droplets using rotating membrane emulsification. J. Colloid Interface Sci. 2006, 299, 396.

(12) Schadler, V.; Windhab, E.J. Continuous membrane emulsification by using a membrane system with controlled pore distance. Desalination 2006, 189, 130.

(13) Manga, M.S.; Cayre, O.J.; Williams, R.A.; Biggs, S.; York, D.W. Production of solidstabilised emulsions through rotational membrane emulsification: influence of particle adsorption kinetics. Soft Matter 2012, 8, 1532.

(14) Zhu, J.; Barrow, D. Analysis of droplet size during crossflow membrane emulsification using stationary and vibrating micromachined silicon nitride membranes. J. Membr. Sci. 2005, 261, 136.

(15) Holdich, R.G.; Dragosavac, M.M.; Vladisavljević, G.T.; Kosvintsev, S.R. Membrane emulsification with oscillating and stationary membranes. Ind. Eng. Chem. Res. 2010, 49, 3810. 
(16) Egidi, E.; Gasparini, G.; Holdich, R.G.; Vladisavljević, G.T.; Kosvintsev, S.R.

Membrane emulsification using membranes of regular pore spacing: Droplet size and uniformity in the presence of surface shear. J. Membr. Sci. 2008, 323, 414.

(17) Mackley, M.R.; Stonestreet, P. Heat transfer and associated energy dissipation for oscillatory flow in baffled tubes. Chem. Eng. Sci. 1995, 50, 2211.

(18) Wong, H.W.; Baird, M.H.I. Fluidisation in a pulsed gas flow. Chem. Eng. J. 1971, 2, 104.

(19) Finnigan, S.M.; Howell, J.A. The effect of pulsed flow on ultrafiltration fluxes in a baffled tubular membrane system. Desalination 1990, 79, 181.

(20) Paquet, D.A.; Ray, W.H. Tubular reactors for emulsion polymerization: I. Experimental investigation. AIChE J. 1994, 40, 73.

(21) Angelov, G.; Gourdon, C. Turbulent flow in pulsed extraction columns with internals of discs and rings: Turbulent kinetic energy and its dissipation rate during the pulsation. Chem. Eng. Process. 2009, 48, 592.

(22) Lau, A.; Crittenden, B.D.; Field, R.W. Enhancement of liquid phase adsorption column performance by means of oscillatory flow: an experimental study. Sep. Purif. Technol. 2004, 35, 113.

(23) Dowding, P.J.; Goodwin, J.W.; Vincent, B. Production of porous suspension polymer beads with a narrow size distribution using a cross-flow membrane and a continuous tubular reactor. Colloids and Surfaces A. 2001, 180, 301. 
(24) Williams, R.A.; Peng, S.J.; Wheeler, D.A.; Morley, N.C.; Taylor, D.; Whalley, M.; Houldsworth, D.W. Controlled production of emulsions using a crossflow membrane. Chem. Eng. Des. A. 1998, 76, 902.

(25) Schröder, V.; Behrend, O.; Schubert, H. Effect of Dynamic Interfacial Tension on the Emulsification Process Using Microporous Ceramic Membranes. J. Colloid Interface Sci. 1998, 202, 334.

(26) Salon, S.; Armenio, V.; Crise, A. A numerical invetsigation of the Stokes boundary layer in the turbulent regime. J. Fluid Mech. 2007, 570, 253.

(27) Nakashima, T.; Shimizu, M.; Kukizaki, M. Particle control of emulsion by membrane emulsification and its applications. Adv. Drug Del. Rev. 2000, 45, 47. 
List of Tables

Table 1 Types of flow found during oscillation

Table 2 Viscosity of the continuous phase and interfacial tension at the aqueous/oil phase interface used for drop size modelling

Table 3 Oscillating flow conditions and dispersed phase injection rate when using 20 micron pore size membrane to investigate pulsing through membrane pores 


\section{List of Figures}

Figure 1 Illustration of experimental equipment for the generation of liquid drops using pulsed continuous phase flow

Figure 2 (a) Median drop size and (b) span of distributions vs. frequency for duplicate and triplicate tests conducted using a $20 \mu \mathrm{m}$ pore size membrane with $1.6 \mathrm{~mm}$ amplitude pulse at $72 \mathrm{~mL} \mathrm{~min}^{-1}$ flow rate of continuous phase and $5 \mathrm{~mL} \mathrm{~min}{ }^{-1}$ flow rate of dispersed phase (7\% O/W emulsion)

$\begin{array}{ll}\text { Figure } 3 & \text { (a) Median drop size and (b) span of distributions vs. dispersed phase injection }\end{array}$ rate using a $10 \mu \mathrm{m}$ pore size membrane with $1.6 \mathrm{~mm}$ amplitude pulse and 30 $\mathrm{Hz}$ frequency at $30 \mathrm{~mL} \mathrm{~min}^{-1}$ flow rate of continuous phase. The dispersed phase concentration obtained in a single pass operation is marked on figures and ranges from 1.6 to $44.8 \%$

Figure 4 Microscope images of drops produced from: (a) $0.5 \mathrm{~mL} \mathrm{~min}^{-1}$ dispersed phase flow rate and (b) $9.7 \mathrm{~mL} \mathrm{~min}^{-1}$ flow rate using the same conditions described in Figure 3

Figure 5 Malvern Mastersizer particle size distribution of image shown in Figure 4(b) using the Multiple Narrow Modes analysis model

Figure 6 The variation of median drop size with frequency using a $10 \mu \mathrm{m}$ pore size membrane with $1.6 \mathrm{~mm}$ amplitude pulse at 30 and $72 \mathrm{~mL} \mathrm{~min}^{-1}$ flow rate of continuous phase and $4 \mathrm{~mL} \mathrm{~min}^{-1}$ flow of dispersed phase (5.3 to $12 \% \mathrm{O} / \mathrm{W}$ emulsion in a single pass). The predictions made by the shear-capillary model 
using interfacial tensions of 2.5 and $4 \mathrm{mN} \mathrm{m}^{-1}$ are shown by solid and dashed line, respectively.

$\begin{array}{ll}\text { Figure } 7 & \text { (a) The variations of median drop size and (b) span of distributions with }\end{array}$ oscillatory Reynolds number using a $20 \mu \mathrm{m}$ pore size membrane with various frequencies and amplitudes at $72 \mathrm{~mL} \mathrm{~min}^{-1}$ flow rate of continuous phase and $5 \mathrm{~mL} \mathrm{~min}^{-1}$ flow of dispersed phase (5.3\% O/W emulsion in a single pass); the error bars indicate the range of results from repeated experiments as illustrated in Figure 2 
Table 1 Types of flow found during oscillation

\begin{tabular}{|l|l|}
\hline \multicolumn{1}{|c|}{ Type of flow } & Oscillatory Reynolds number \\
\hline$<100$ & Laminar \\
\hline 100 to 550 & Disturbed laminar \\
\hline 550 to 800 & Intermittent regime \\
\hline 800 to 1800 & Some turbulence \\
\hline 1800 to 3640 & Turbulent for most of the cycle \\
\hline$>3460$ & Turbulent all of the cycle \\
\hline
\end{tabular}


Table 2 Viscosity of the continuous phase and interfacial tension at the aqueous/oil phase interface used for drop size modelling

\begin{tabular}{|l|c|c|}
\hline \multicolumn{1}{|c|}{ Continuous phase } & $\begin{array}{c}\text { Viscosity } \\
(\mathbf{m P a})\end{array}$ & $\begin{array}{c}\text { Interfacial tension } \\
\left(\mathbf{m N ~ m}^{\mathbf{- 1}}\right)\end{array}$ \\
\hline 2\% w/w Tween 20 & 1 & 2.5 \\
\hline 2\% w/w Tween 20 with 0.4 wt. \% MHC & 30 & 2.5 \\
\hline In previous work & & \\
\hline 2\% w/w Tween 20 & \multicolumn{2}{|c|}{$4^{*}$} \\
\hline
\end{tabular}

*Measured using the Du Nouy ring method. 
Table 3 Oscillating flow conditions and dispersed phase injection rate when using 20 micron pore size membrane to investigate pulsing through membrane pores

\begin{tabular}{|c|c|c|c|c|c|c|c|}
\hline Frequency & $\begin{array}{c}\text { Amplitude } \\
\\
\text { (mm) }\end{array}$ & $\begin{array}{l}\text { Shear } \\
\text { stress } \\
\text { (Pa) }\end{array}$ & $\begin{array}{c}\text { Dispersed } \\
\text { flow } \\
\text { (mL/min) }\end{array}$ & $\begin{array}{c}\text { Median } \\
\text { diameter } \\
(\mu \mathrm{m})\end{array}$ & Span & $\begin{array}{l}\text { Continuous } \\
\text { phase } \\
\text { viscosity } \\
\text { (Pa s) }\end{array}$ & $\begin{array}{c}\text { Emulsion } \\
\text { concentration } \\
(\% \mathrm{v} / \mathrm{v})\end{array}$ \\
\hline 0 & 0 & $\begin{array}{l}\sim 0 \\
\end{array}$ & 0.5 & 274 & 0.75 & 0.001 & 1.7 \\
\hline 0 & 0 & $\sim 0$ & 5 & 337 & 1.1 & 0.001 & 15 \\
\hline 10 & 1.6 & 0.79 & 0.5 & 47 & 0.57 & 0.001 & 1.7 \\
\hline 10 & 1.6 & 0.79 & 5 & 87 & 0.71 & 0.001 & 7.0 \\
\hline 10 & 1.6 & 0.79 & 15 & 217 & 0.77 & 0.001 & 21 \\
\hline 15 & 1.6 & 1.5 & 5 & 65 & 0.59 & 0.001 & 7.0 \\
\hline 15 & 1.6 & 1.5 & 15 & 85 & 0.51 & 0.001 & 21 \\
\hline 20 & 1.6 & 2.2 & 5 & 57 & 0.76 & 0.001 & 7.0 \\
\hline 20 & 1.6 & 2.2 & 15 & 74 & 0.52 & 0.001 & 21 \\
\hline 30 & 0.6 & 10 & 5 & 140 & 0.80 & 0.030 & 15 \\
\hline 30 & 1.3 & 18 & 5 & 51 & 0.55 & 0.030 & 15 \\
\hline 30 & 3.8 & 54 & 5 & 54 & 0.45 & 0.030 & 15 \\
\hline
\end{tabular}




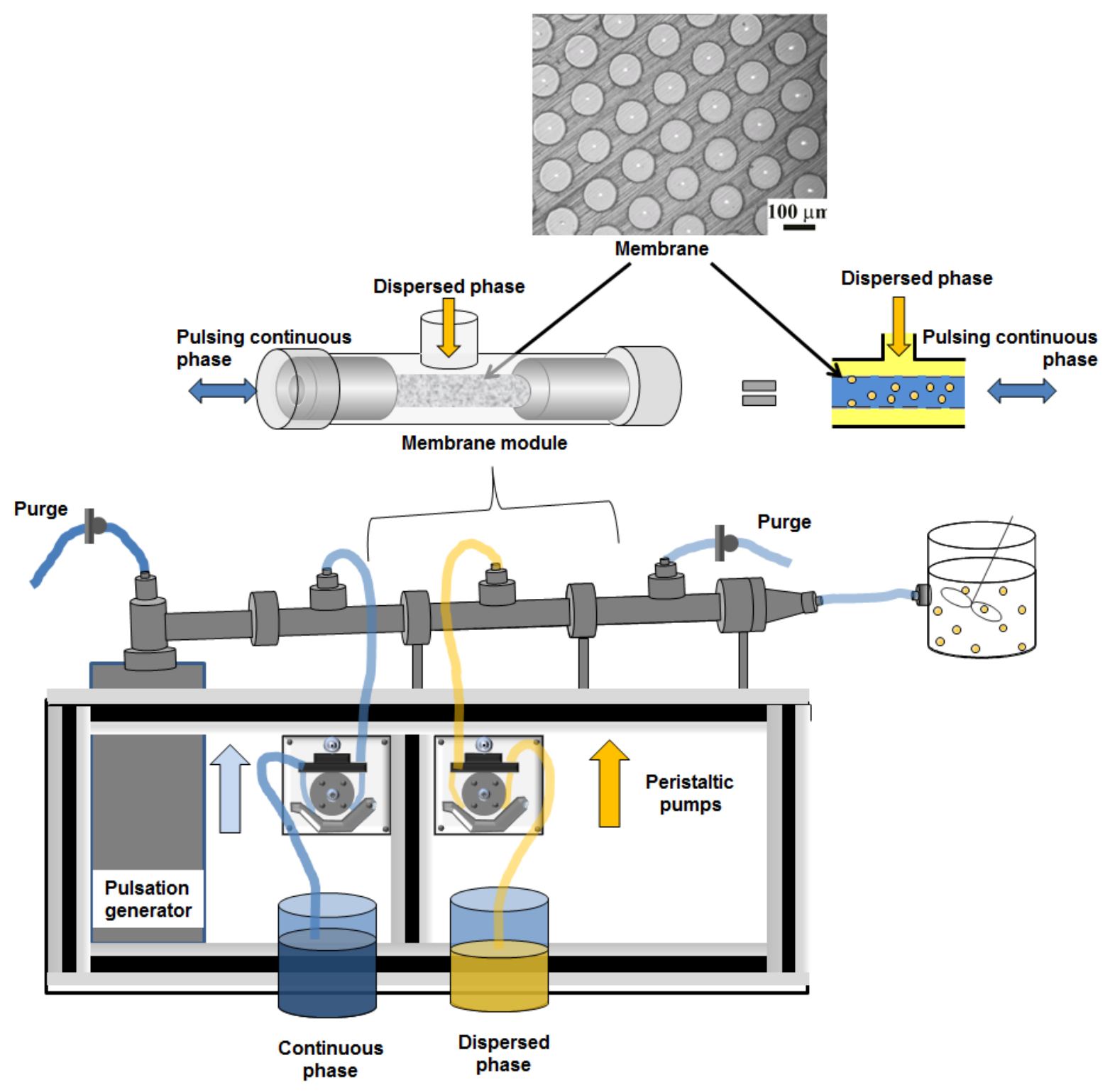

Figure 1 Illustration of experimental equipment for the generation of liquid drops using pulsed continuous phase flow 
(a)

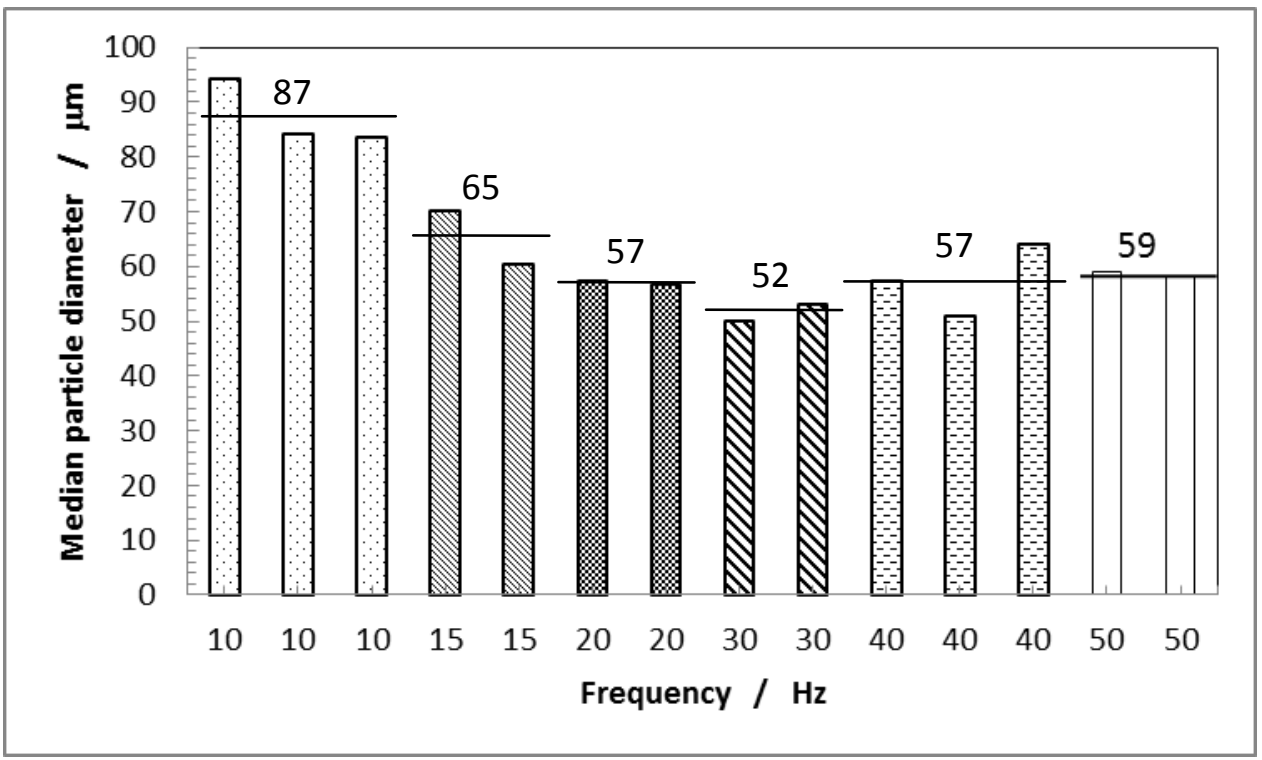


(b)

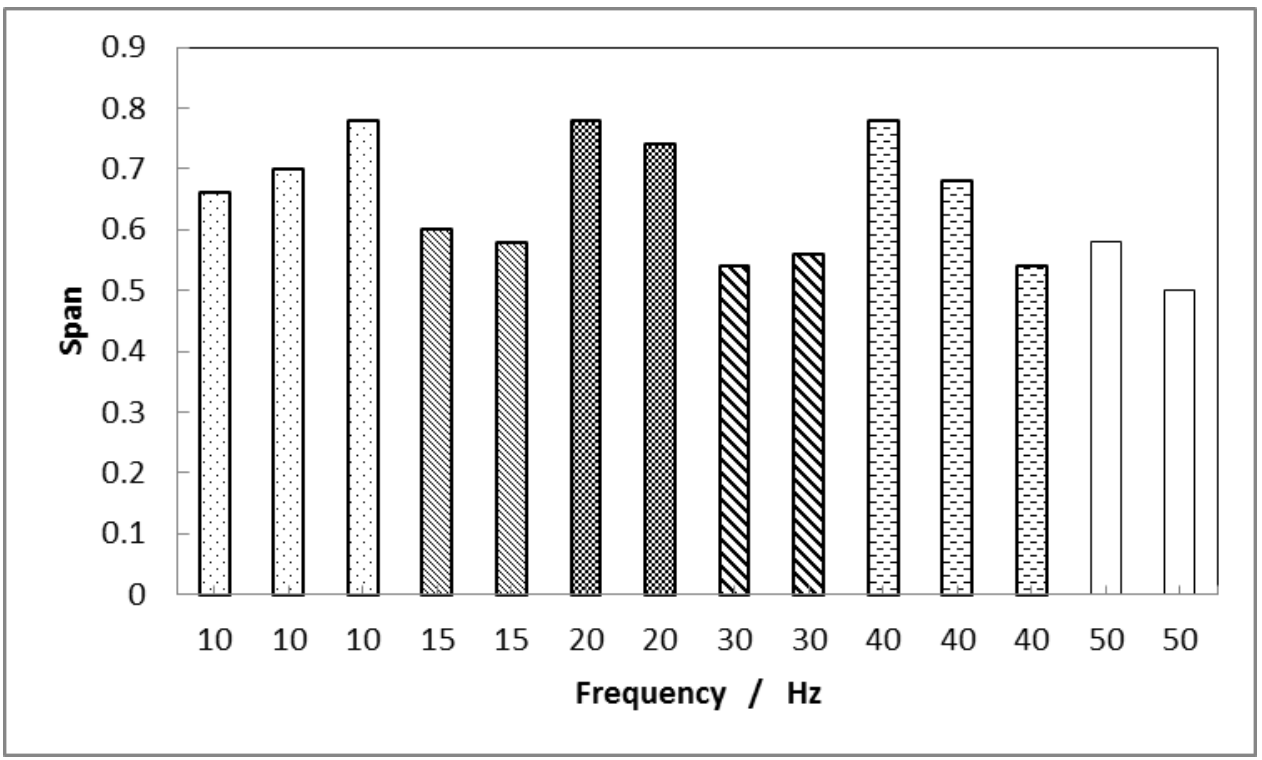

Figure 2 (a) Median drop size and (b) span of distributions vs. frequency for duplicate and triplicate tests conducted using a $20 \mu \mathrm{m}$ pore size membrane with $1.6 \mathrm{~mm}$ amplitude pulse at $72 \mathrm{~mL} \mathrm{~min}^{-1}$ flow rate of continuous phase and $5 \mathrm{~mL} \mathrm{~min}{ }^{-1}$ flow rate of dispersed phase (7\% $\mathrm{O} / \mathrm{W}$ emulsion) 
(a)

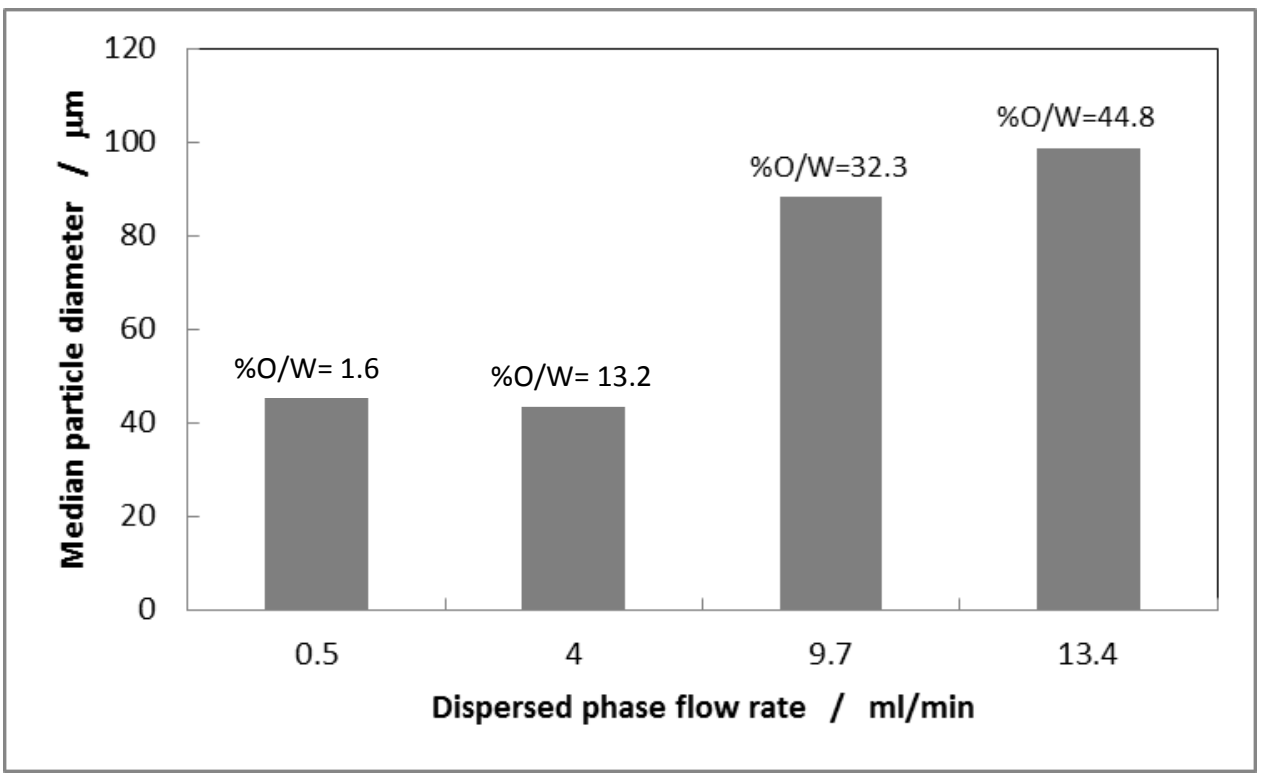


(b)

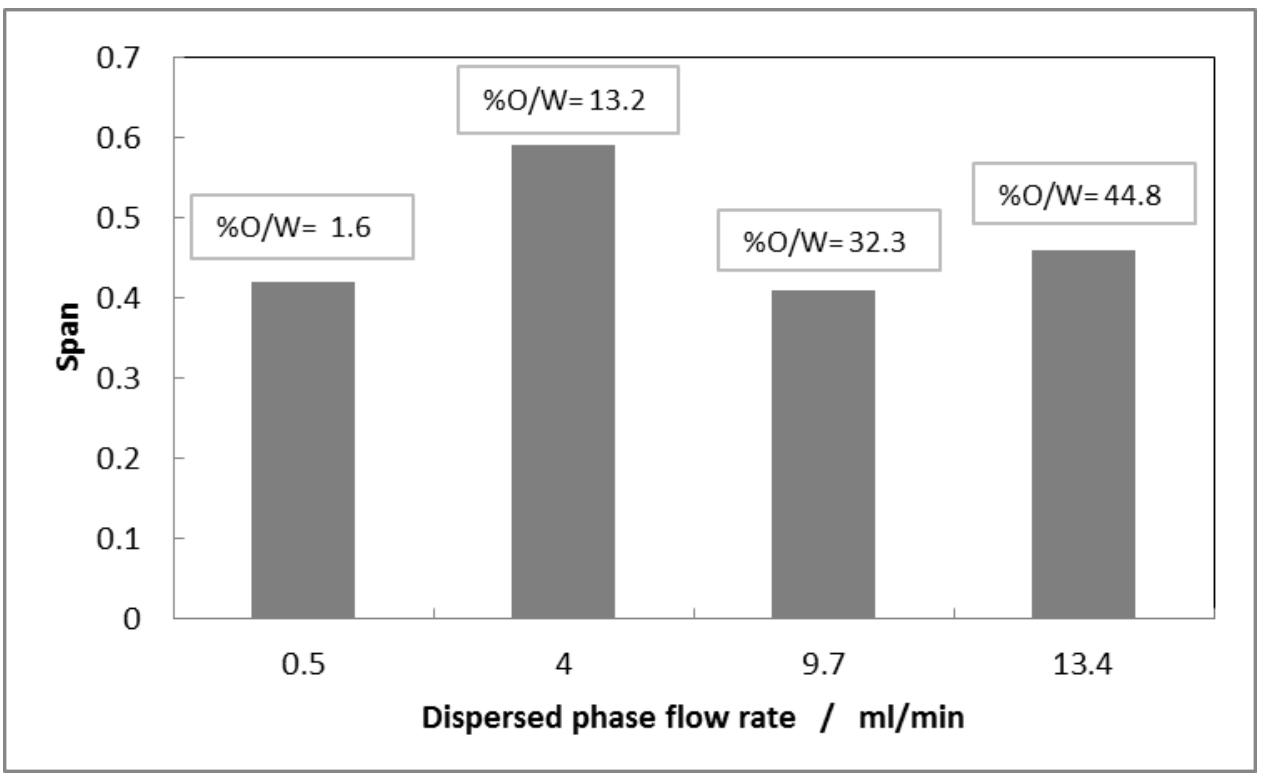

Figure 3 (a) Median drop size and (b) span of distributions vs. dispersed phase injection rate using a $10 \mu \mathrm{m}$ pore size membrane with $1.6 \mathrm{~mm}$ amplitude pulse and 30 $\mathrm{Hz}$ frequency at $30 \mathrm{~mL} \mathrm{~min}^{-1}$ flow rate of continuous phase. The dispersed phase concentration obtained in a single pass operation is marked on figures and ranges from 1.6 to $44.8 \%$ 
(a)

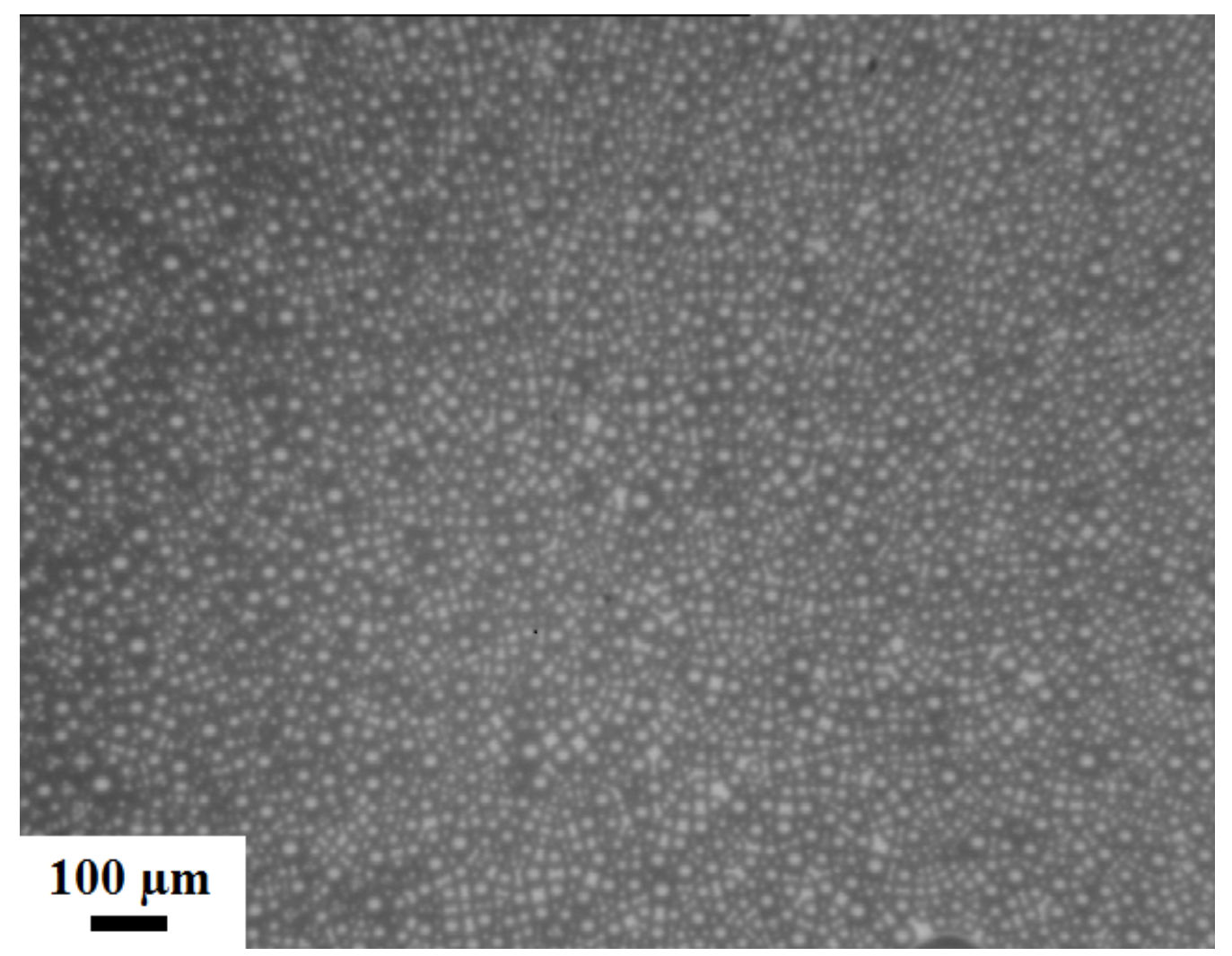


(b)

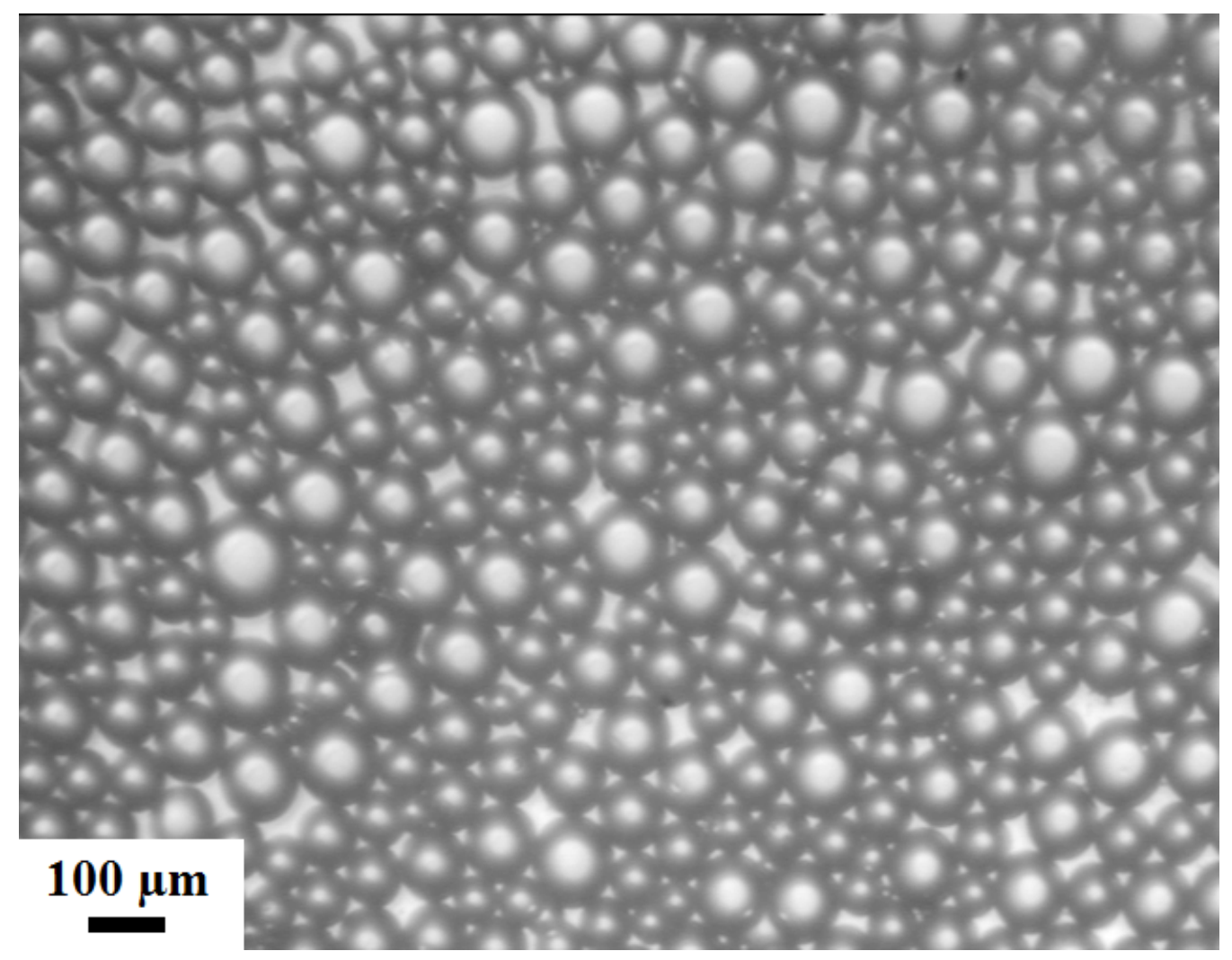

Figure 4 Microscope images of drops produced from: (a) $0.5 \mathrm{~mL} \mathrm{~min}^{-1}$ dispersed phase flow rate and (b) $9.7 \mathrm{~mL} \mathrm{~min}^{-1}$ flow rate using the same conditions described in Figure 3 


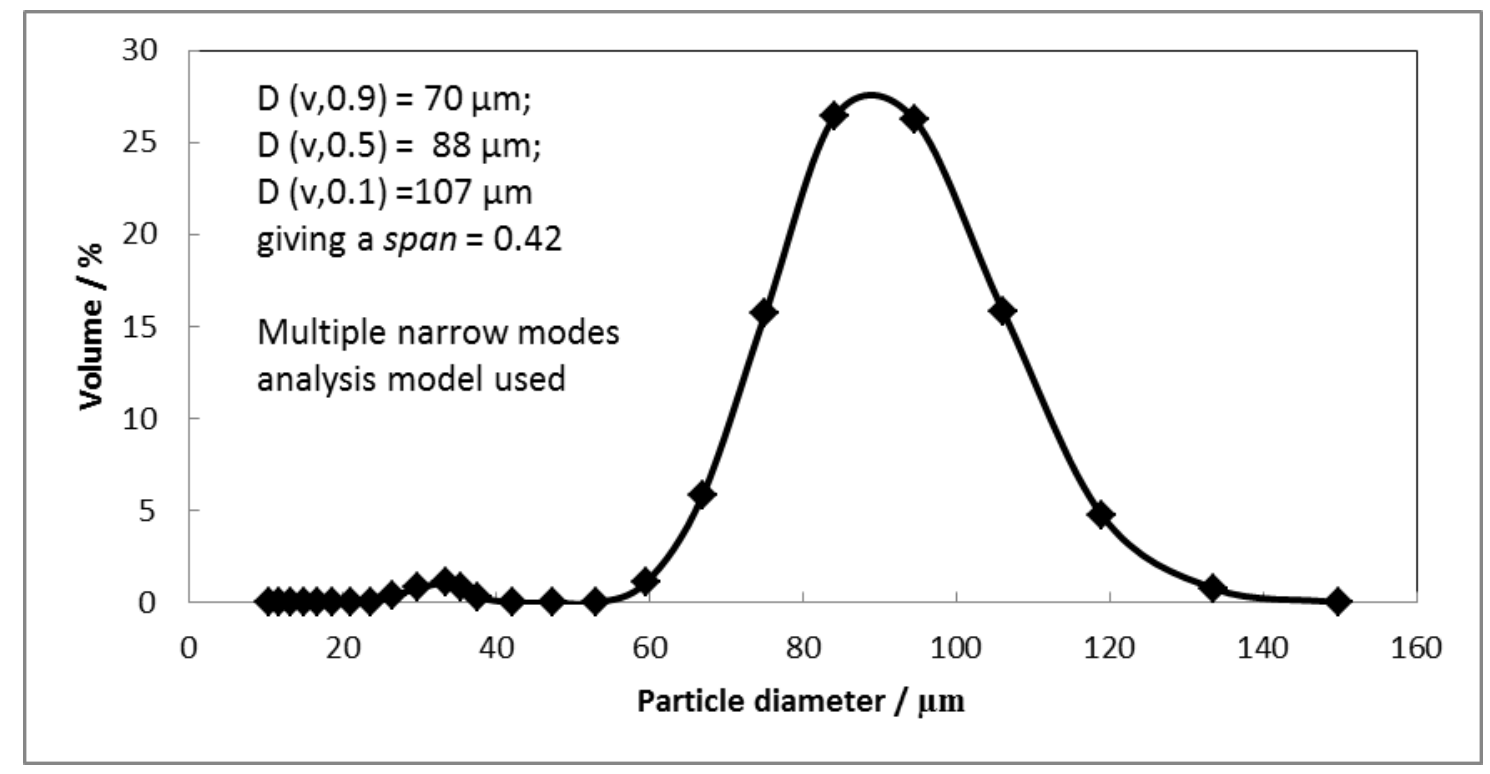

Figure 5 Malvern Mastersizer particle size distribution of image shown in Figure 4(b) using the Multiple Narrow Modes analysis model 


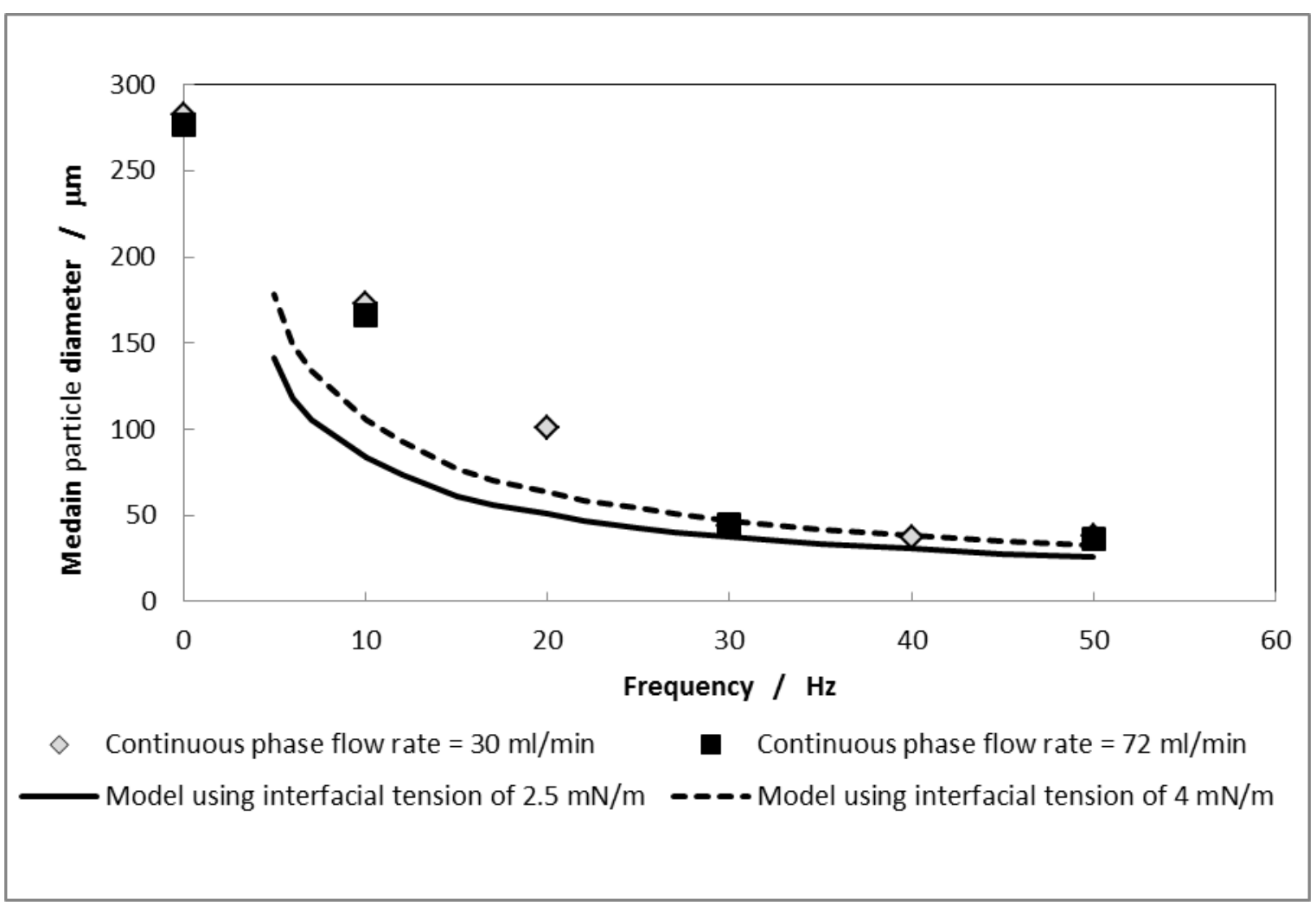

Figure 6 The variation of median drop size with frequency using a $10 \mu \mathrm{m}$ pore size membrane with $1.6 \mathrm{~mm}$ amplitude pulse at 30 and $72 \mathrm{~mL} \mathrm{~min}^{-1}$ flow rate of continuous phase and $4 \mathrm{~mL} \mathrm{~min}^{-1}$ flow of dispersed phase (5.3 to 12\% O/W emulsion in a single pass). The predictions made by the shear-capillary model using interfacial tensions of 2.5 and $4 \mathrm{mN} \mathrm{m}^{-1}$ are shown by solid and dashed line, respectively 
(a)

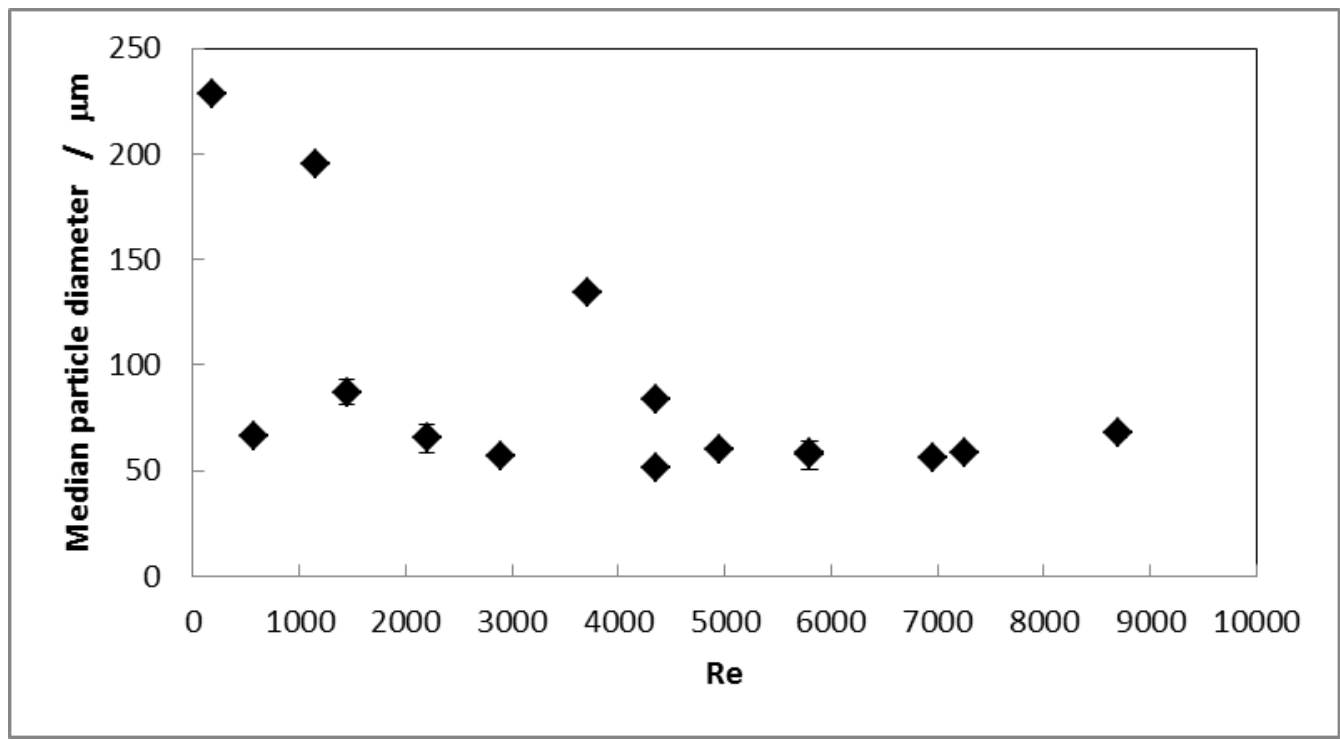


(b)

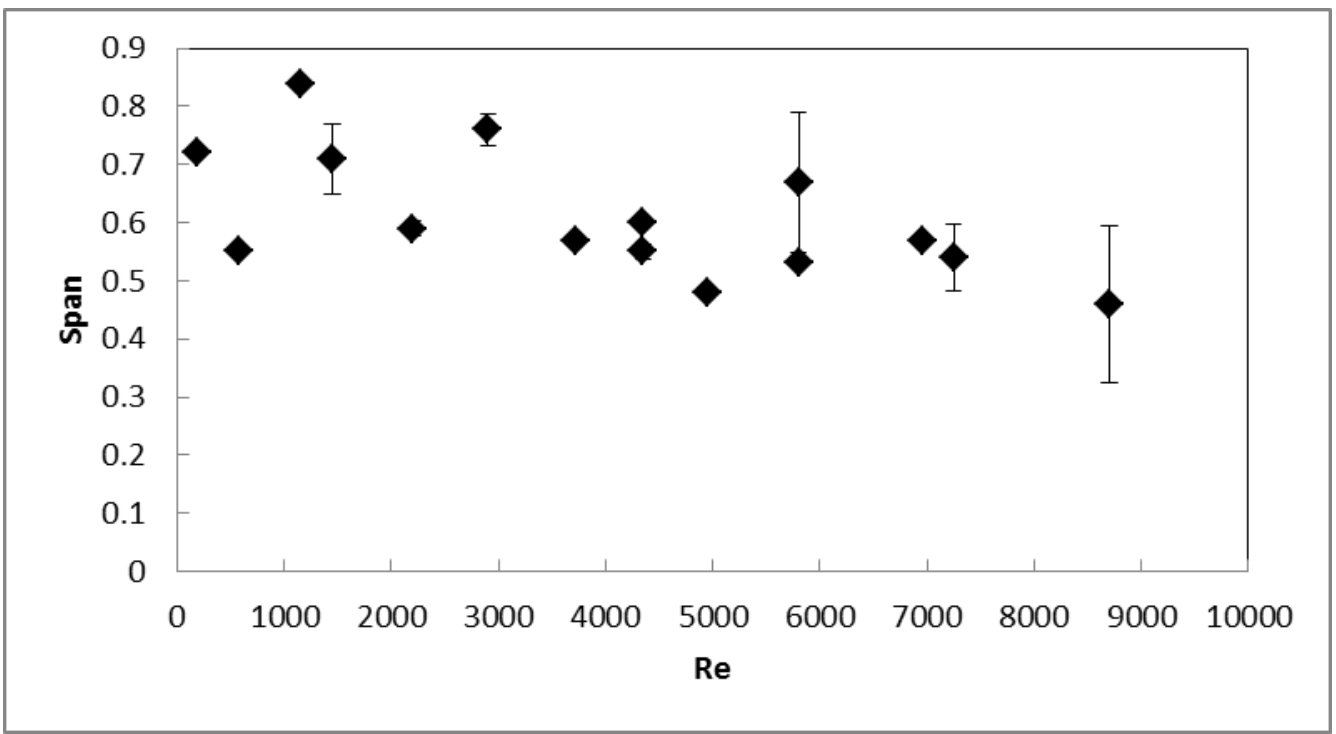

$\begin{array}{ll}\text { Figure } 7 & \text { (a) The variations of median drop size and (b) span of distributions with }\end{array}$ oscillatory Reynolds number using a $20 \mu \mathrm{m}$ pore size membrane with various frequencies and amplitudes at $72 \mathrm{~mL} \mathrm{~min}^{-1}$ flow rate of continuous phase and $5 \mathrm{~mL} \mathrm{~min}^{-1}$ flow of dispersed phase (5.3\% O/W emulsion in a single pass); the error bars indicate the range of results from repeated experiments as illustrated in Figure 2 